\title{
Does size matter - How should trustees approach the new member trustee requirement?
}

Received (in revised form): 20th September, 2006

\begin{abstract}
Vivien Cockerill
is a partner in the pensions team at Wragge and Co. LLP solicitors. She was educated in York and read law with French at Birmingham University obtaining an LLB honours degree in 1984. She trained at Sacker \& Partners in London and qualified as a solicitor in 1987. She has specialised in pensions law ever since. She moved to Wragge and Co. in 1989, becoming a partner in 1992. She advises many trustees of occupational pension schemes of different sizes and with different trustee structures. She is a well-known speaker on the pensions lecture circuit and a former member of the Association of Pension Lawyers main committee. She was a Board member of TPAS, The Pensions Advisory Service from 2000 to 2006 and was involved in their review of their governance structure.
\end{abstract}

Abstract This paper examines the new requirements for member-nominated trustees under the Pensions Act 2004 including the requirement to involve pensioners in the process. It considers how the new requirements may best be applied in practice to improve the make up of the trustee board drawing on examples of good governance from the corporate environment and current thinking on leadership.

Pensions (2006) 12, 12-17. doi:10.1057/palgrave.pm.5950037

Keywords: Pensions Act 2004, trustees, member-nominated trustees, member-nominated directors, trustee governance, pensioners

\section{Background}

The requirements in the Pensions Act $2004^{1}$ relating to the nomination and selection of member-nominated trustees (MNTs) ${ }^{2}$ came into force in April this year. Trustees must ensure within a reasonable period that suitable arrangements are put in place to provide that at least one-third of the trustees are MNTs and that these arrangements are implemented. The accompanying Code of Practice ${ }^{3}$ has been laid before Parliament but will not come into force until the Autumn. The Pensions Regulator has also produced additional guidance on its website. ${ }^{4}$

The Department of Work and Pensions has moved away from detailed prescription and towards flexibility, giving trustees the scope to

Correspondence: Vivien Cockerill, Wragge \& Co. LLP, 55 Colmore Row, Birmingham B3 2AS, UK

Tel: 01212609834

Fax: 08709041099

E-mail: Vivien_Cockerill@wragge.com tailor their arrangements to suit the size and nature of their individual occupational pension schemes. The Code of Practice does not specify how trustees should comply with the new legislative requirements. Instead, it sets out three principles that trustees must take into account when they are deciding on the arrangements to put in place

The principles that have been identified are:

$$
\begin{aligned}
& \text { - proportionality; } \\
& \text { — fairness; and } \\
& \text { — transparency. }
\end{aligned}
$$

The aim of these principles is to ensure that trustees put arrangements in place, which are appropriate to their pension schemes, that the arrangements treat all members fairly and that the trustees clearly communicate details of the arrangements to members.

The Pensions Regulator expects trustees to put suitable arrangements in place within a reasonable period from when the requirements first apply. 
Initially, the requirements will not apply to all pension schemes and the date by which trustees must comply with the new requirements will vary depending on whether the pension scheme has an opt-out in place under which the employer effectively currently determines the make up of the trustee body. Such opt-outs are not possible under the new regime.

Trustees whose pension schemes have opt-outs in place do not have to put arrangements in place until the expiry of the opt-out or 31st October, 2007 (whichever is earlier). But this does not mean that trustees in this position should do nothing. From Spring 2007 at the latest, these trustees should be considering what arrangements they need to be put in place and how far these will differ from their existing arrangements. The Pensions Regulator expects the trustees to consider new arrangements before the expiry of the opt-out.

For other trustees who do not have opt-outs in place, action needs to be taken now to ensure that suitable arrangements are put in place. There is a slight relaxation for MNTs appointed under the Pensions Act 1995 (ie following the previous statutory rules and not under an employer opt-out). These MNTs will continue to count as MNTs under the Pensions Act 2004 until their term of office expires. Therefore, although suitable arrangements need to be put in place, which meet the new requirements, trustees do not need to run the nomination and selection process unless and until there is a vacancy for an MNT.

Where pension scheme rules already require more than one-third of the trustees to be MNTs, that proportion of MNTs will continue to be required.

The responsibility for compliance with the MNT requirements clearly lies with the trustees, but the Pensions Regulator does recommend consultation with the employer.

\section{The need to involve pensioners}

Putting suitable arrangements in place does not necessarily mean making new arrangements. Trustees should consider whether their current arrangements (or any parts of them) are still appropriate to meet the requirements of the new regime. Many employer opt-outs were put in place to allow existing well-established pension scheme specific member trustee arrangements to continue.

For the vast majority of trustee boards, a new requirement is the need to involve pensioner members. The new requirements specify that all active members and all pensioner members (or an organisation that adequately represents them) must be involved in the nomination process. The nomination process identifies the candidates for the selection of MNTs. The subsequent selection process must involve some or all of the members. There is no requirement that all active and pensioner members are involved in the selection process. Pensioner members do not have to be involved at all in the selection process. There is no requirement to involve deferred members in either the nomination or the selection process (except where there are no active or pensioner members).

Although there is no requirement to appoint a pensioner trustee, any consideration of the three overriding principles set out above, namely proportionality, fairness and transparency, is likely to lead to the conclusion that for most defined benefit pension schemes at least one pensioner trustee (or pensioner-nominated trustee) is appropriate. Why? Most defined benefit pension schemes are maturing quickly with the result that nonactive members far outnumber active members. There is expressly no requirement to reflect the proportions of each category of membership in the make up of the trustee board, but fairness is likely to lead to a conclusion that there is a need for pensioner presence or representation on the trustee board.

This is particularly so when the operation of the Pension Protection Fund (PPF) and the new winding-up priorities since April 2005 are taken into account. Previously, the pensioners' benefits ranked ahead of benefits for some deferred and active members and increases ranked alongside other benefits for deferred and active members, but the PPF does not guarantee pre-1997 pension increases. Pensioners would automatically lose the 
right to these increases if their pension scheme is underfunded and the PPF assumes responsibility for it on employer insolvency, so they have a clear interest in the good governance of the pension scheme.

One possibility where arrangements otherwise comply with the requirements is simply to create an additional vacancy or vacancies for the appointment of one or more pensionernominated trustees as additional MNTs. Although this appears to be a straightforward and practical solution, and it would ensure that the trustees are complying with the new requirements, consideration should be given to how this approach could impact on the way the trustee board will function. If trustees make ad hoc amendments to their arrangements to ensure compliance in this way, it could lead to an ineffective trustee board, which cannot function efficiently due to increased size (especially if, for example, the company response is to appoint an additional trustee or two for every MNT that is appointed).

\section{Looking at the new requirements more broadly: Is there a right size for trustee boards?}

Trustee boards have been increasing in size over the last few years and this trend could be set to continue as trustees redesign their existing arrangements to involve pensioners.

Is this the right way to move forward? Do larger trustee boards result in better run pension schemes through more member representation or do they result in inefficiency and lack of cohesion?

The question of the optimum size for a team is not new and has been discussed in business and academic fields for many years. Maximillian Ringlemann, a French agricultural engineer born in 1861, carried out an experiment in which he used groups made up of different numbers of people to pull on a rope. He noticed that the more people pulled on the rope, the less individual effort was exerted by each team member. The result of the experiment goes against the general perception that the more people you have in a team, the greater the performance and effort of the team. Ringlemann described this as 'social loafing' where an individual's lack of effort is hidden by the rest of the team.

In the context of a trustee board, the larger the trustee board, the more scope there is for the 'Ringlemann effect' to manifest itself. For example, in a large trustee board, how easy is it to ascertain whether individual trustees are actively participating in the decision-making process or whether they are simply following the majority view? The larger the board, the easier it is to hide behind other trustees. If trustees fail to engage in the decision-making process, they are arguably not discharging their duties appropriately, but in a large trustee board, are these shortcomings picked up and dealt with or are they hidden and left to fester? It should be picked up by evaluation of the performance of trustees, but it is arguable that the larger the trustee board, the greater the risk of 'social loafing' going unnoticed.

Several trustee boards of which we have experience have over ten members, some over 15 . A recent paper in Fortune magazine ${ }^{5}$ suggests that the optimal number for a decision-making team is 4.6. This suggests that increasing the size of the trustee board still further should be avoided, but does this also mean that these boards need to be reduced in size? Although smaller trustee boards can be more effective, there are several other factors that need to be considered when trying to create a 'dream team'. Size is not the only thing that matters.

The new requirements represent an opportunity for existing trustees to decide how the trustee board will work best. The starting point is the statutory requirement for one-third MNTs with a minimum of two trustees. Most employers will still want a trustee body's majority to be employer-appointed if the deed allows, so in practice the minimum size for a pension scheme trustee board is five. Why have more?

The reason for a larger trustee board could be that member trustees are selected from each part of a business (geographical or otherwise) to ensure that the interests of the membership as a 
whole are represented, which results in more than two MNTs. The Pensions Regulator's Code of Practice expressly recognises the use of constituencies in this way. Typically, the employer will wish to appoint the majority of the people at the trustee table, even though all trustees are of course under the same obligations under trust law. So how can those bigger trustee boards ensure they are effective?

\section{Back to basics: What makes a trustee board effective?}

Ringelmann's research on teams was revisited recently by Jennifer S. Mueller, a management professor from The Wharton School ${ }^{6}$ who makes an interesting comment on 'social loafing'. Mueller says 'after about 5 people there are diminishing returns on how much people will pull, but people, unless they are not motivated or the task is arbitrary, will not want to show social loafing'.

Mueller identifies three considerations for putting together an effective team:

- What type of task will the team engage in? In a sales team for instance, the effort is individual and the people are not interdependent.

On the other hand, if the task is cleaning a stadium, 30 people will do the job faster than five people.

- What is the team composition? What are the skills needed for the task? This includes work style and background knowledge.

- Size: Identifying the optimum size of team has been the subject of much study. The outcome seem to be that the best number of people for the team depends on the task and the role of each team member but it is likely to be between five and 12 .

Bigger trustee boards work effectively where they have a developed approach to governance and use committees with well-defined functions and terms of reference. Where individuals are allocated roles and responsibilities, there is much less scope for 'social loafing': partly because the expectations of them become more specific and partly because they effectively form a smaller sub-team in which the Ringlemann effect does not occur. The members of the investment committee, for instance, know that they must participate in its work and they take responsibility for reporting back to the full trustee board.

\section{What is the task of the trustee board?}

The trustees' role is to deliver the right benefits to the right members at the right time. To achieve this they must:

- collect contributions and invest and safeguard pension scheme assets;

- maintain proper accounts and records; and

- comply with the law.

Of course trustees do not carry out all their functions themselves. They delegate to investment managers and administrators among others. They rely on advice from actuaries, auditors and lawyers. Carrying out their role properly depends on their effective management of the pension scheme via systems which ensure that appropriate controls exist, and that regulator monitoring takes place.

The trustees need to ask themselves to what extent they can best carry out their role through delegation to committees which may have special expertise, or more time available to spend on an issue. They then need to decide on the make up of the committee, the extent of the delegation, and the reporting and monitoring arrangements.

\section{What are the skills required?}

The composition of a trustee board is an important factor in determining whether or not the board will be successful and effective. In a business context, individuals will usually only be appointed to a board of directors if they have skills that are needed for the business. Trustees could usefully adapt some of the general principles applied in a business context and apply them in the selection of trustees. A recent Dti paper $^{7}$ gives examples of different views of effective governance to encourage best practice and creative thinking. 
One case is Mothercare where the Board decided they particularly wanted a Non-Executive director with a marketing background and also recent practical experience of their business. They appointed Karren Brady, Chief Executive of Birmingham City Football Club and a mother of two. Although she had no experience of Financial Times Stock Exchange (FTSE) Boards, and so was not perhaps an obvious choice, she was, in the words of their chairman

'...otherwise ideal for the job. Importantly, she can bring to the table the perspective of a recent Mothercare customer and take a fresh look at strategy from that viewpoint'.

Her skills and experience matched the need they had identified.

Another case referred to in the Dti paper is that of Formscape, a document process automation company. Following a buy-out in 2003, the directors spent time considering the skills and the perspective they needed from their sector of chairman. They appointed Don Cruickshank, the former CEO of the London Stock Exchange. He did not have particular experience of their sector of business. CEO Malcolm Peden explained

'we decided to appoint Don Cruickshank because of his broad experience in a number of industries, his public market knowledge... an Initial Public Offering is part of the company's medium-term business development plan'.

Ensuring that there is the correct skills set in a trustee board is more difficult. This is because it is impossible to control which members put themselves forward for appointment as MNTs (and in many pension schemes there may not even be enough volunteers to fill the number of vacancies, but that is outside the scope of this paper). It is also worth remembering that trustee boards have not previously had any say over the appointment of new trustees. Under the previous regime, either the whole trustee board was appointed under rules approved by the employer, if there was an opt-out, or member trustees were appointed by ballot. Going forward, the correct composition of the trustee board will be an issue upon which the employer and trustees will need to consult and (ideally) agree. It is, however, important to remember that each individual will have something different to offer (which could be due to their background within the business or their interests outside it). We have experience of the stereotypical 'one-issue' pensioner trustee who is focused only on pension increases but we also have good experience of committed pensioner trustees who are less conflicted than other trustees and also less timeconstrained.

One issue for trustees designing new arrangements for selection of member trustees is whether they should go for 'democracy', that is, one member one vote or 'control' via a selection panel which is entrusted with choosing the best candidate for the role. In many cases, previous experience and company culture will lead to a preference for one or another approach, but a selection panel has much to recommend it and fits more with good governance elsewhere. The Pensions Regulator mentions in its guidance the possibility of a different approach being adopted for actives and pensioners.

Vodaphone uses a checklist for future Board appointments, which could serve as a model pension schemes could adapt:

- What's the business requirement going forward?

- What skills, knowledge, experience are we looking for or do we feel we are missing?

- What's the overall balance of the board in terms of age, profile, gender, and geographical spread?

- How does any new appointment relate to longer term succession planning?

- What's the availability of people with the skill-sets, experience and market credibility we need?

- Select the best available candidate ${ }^{8}$

So what skills does the trustee board require? An understanding of investment matters and financial matters is important. An understanding of the human resources context in the company would be desirable. For some, pension schemes MNTs are seen as key to communication with the membership so good communication skills and a 
high profile in the business, perhaps via a union role, would be important.

As part of the exercise of reviewing the arrangements for MNTs, the trustees could establish with the company how it identifies company-nominated trustees and whether some of those skills will be found on the company trustee side of the table. Companies are familiar with working in compliance with good governance principles and trustees will often find a positive reception to their suggestions.

The choice of Chairperson is of course key to the effective working of the trustee board. The approach and expectations of the Chairperson have a direct impact on how the trustee board works as a whole.

Having identified and appointed the best candidates, individual trustees must then take responsibility for their own training and development. The Pensions Regulator has published a Code of Practice on trustee knowledge and understanding, ${ }^{9}$ which sets out in detail the issues in relation to which trustees must have knowledge and the level of detail to which that knowledge must extend. The effectiveness of the trustee board as a whole is, to a large extent, dependent on the ability of the trustees to understand the difficult and complex issues that arise on a daily basis in the context of a pension scheme. Trustees must be confident in their ability to reach informed decisions. Although the trustees have professional advisers to rely on, it is ultimately the trustees who must make the decisions. They cannot make an informed decision without having a certain level of knowledge.

\section{Size}

Mueller would suggest that only after considering the task of the trustee board and the skills it needs do the trustees start to think about size.

Her guidance would be that a team of over eight or nine people is likely to break down into sub-teams. This might be the right approach a trustee board of nine, for instance, could be broken down into investment committee, audit committee and benefits/administration committee, but how do you ensure a board of 15 trustees are all engaged and motivated?

Wragge \& Co. have carried out a trustee governance survey of 100 or so, their largest clients for the last few years, ${ }^{10}$ and they asked participants to comment on the size of their board: how big is it and should it be bigger or smaller? The majority have trustee boards with between nine and 11 members and regard that as the right size. Those with larger trustee boards generally regard them as too large.

\section{Conclusion}

All trustee boards of pension schemes need to review their composition over the next 12 months or so to comply with the Pensions Act requirements. Most will need to make changes to involve pensioners in the nomination and selection of MNTs for the first time.

This gives existing trustees an opportunity for the first time to consider how they work, and whether they have the best possible composition and size of trustee board.

There has been much discussion over the last few years of the need to improve trustee performance. This legislation represents an opportunity for a step change in effective trustee governance.

\section{References}

1 Sections 241-243 of the Pensions Act 2004 and the Occupational Pensions Schemes (Member-nominated trustees and Directors) Regulations 2006 (SI 2006/714).

2 References to member-nominated trustees also include member-nominated directors, unless otherwise specified.

3 The Pensions Regulator Draft Code of Practice No. 8 Member-nominated trustees and directors - putting in place and implementing arrangements.

4 www.thepensionsregulator.gov.uk.

5 'How to build a great team' by Jerry Useem, Fortune, 1st June, 2006.

6 Is your team too big? Too small? What's the right number? (http://knowledge.wharton.upenn.edu/article. cfm?articleid=1501).

7 Building better boards (www.dti.gov.uk/files/file19615.pdf).

8 Building better boards ( www.dti.gov.uk/files/file19615.pdf).

9 The Pensions Regulator Code of Practice 07 - Trustee Knowledge and Understanding (TKU).

10 www.wragge.com/files/Pensions_Trustee_Nov05.pdf; www. opdu.co.uk/reports.htm (issue 17th November, 2004). 